\title{
LANDSCAPE CHANGES DUE TO QUARRYING ACTIVITIES AS A PROJECT PARAMETER FOR URBAN PLANNING
}

\author{
D. LIPPIELLO, G. ALFARO DEGAN \& M. PINZARI \\ Department of Engineering, University of Roma Tre, Italy.
}

\begin{abstract}
This article presents a procedure to analyse the consequences induced by extractive activities on the surrounding landscape. The objective is to predict the extent of visual interference a given extractive venture will have on the landscape, while taking into account the landscape sensitivity of the area. To this aim, a method is proposed for evaluating the relationship between extractive methods and resultant visual impact by means of a case study in the Lazio region of Italy. Having determined the site for the extractive activities, an annual production target is fixed. In relation to the type of material to be extracted, various options are then selected according to the possible extraction methods and, for each of these, quantitative indicators associated with the resulting visual impact are determined and evaluated. The landscape sensitivity of the area surrounding the site is considered to evaluate the possible effect on the various types of observers who may be present. The procedure described in this article constitutes a concise instrument to be used as a decision-making aid during the planning stage of a quarrying or mining venture. It would equally be of help to the regulatory authorities and to any property developers involved in making building choices, which would be affected by nearby extractive plants or any large construction work in general.

Keywords: corrected visual ratio, degree of intervisibility, exploitation methods, quarries and mining activities, visual impact.
\end{abstract}

\section{INTRODUCTION}

Opencast mine and quarry companies must pay particular attention to any aspects of their activity which impact upon the surrounding area. Many of the main environmental components are affected by both the type of technology utilised and the nature of the tasks performed by the extraction plant machinery [1-3]. Among the physical agents, noise [4] and vibrations are particularly relevant, and their effects have been studied by the scientific community using several different methodologies [5-7]. With regard to atmospheric emissions on the other hand, airborne particulates [8-13] are the main pollutants. In this context, visual impact is an important aspect since, in spite of any work to mitigate the effects on the terrain and to reclaim the land $[14,15]$, it produces changes in the landscape which will nonetheless last for a rather long period of time [16,17]. Quarries are often opened on the slopes of hills and mountains, and the resultant degradation of the landscape may last long after the work has ceased. Whereas the environmental impact of physical and chemical agents may be assessed by means of objective procedures based on the results of on-site measurements, an evaluation of the visual impact of extractive activities is more subjective [18]. Although it is possible to define physical changes in the environment using opportune indicators and parameters [19-21], there is still a degree of subjectivity which would vary according to the perception of the observer. Two aspects of environmental impact must be considered: the physical impact and the impact perceived by an observer. Furthermore, on the basis of knowledge gained in the field [22-25], an attempt has been made to combine these two aspects by means of quantitative and qualitative parameters.

The objective of this article is to define a procedure that may even be used during the planning stage, which provides an evaluation of impact while considering the relationship between the extractive activity itself and the observer. Although much has been learnt with regard to both visual impact

(C) 2015 WIT Press, www.witpress.com

ISSN: 1743-7601 (paper format), ISSN: 1743-761X (online), http://www.witpress.com/journals DOI: $10.2495 /$ SDP-V10-N6-843-862 
mitigation and post-operations reclamation, clearly by far the most efficient approach in terms of visual impact management is to take preventative measures based on a preliminary evaluation of the effects the various possible configurations of the site could produce depending on the extraction method used and the progress of the mining process on site [26].

However, such an approach may be applied not only to aid local authorities to make decisions regarding land use and project planning but also to facilitate choices during the operational phase as well as monitoring the progress of the extraction work.

On the one hand, there is the problem of identifying the best project and exploitation method, which minimises the visual impact for the duration of the mine or quarry's lifetime, i.e. the degree of visual intrusion and change in the landscape.

On the other hand, attention must also be focused on the point of view of those most affected by any visual changes in the landscape, i.e. observers from roads or built up areas in the vicinity which are within sight of the extraction site.

\section{MATERIALS AND METHODS}

\subsection{The evaluation procedure and its application}

The evaluation procedure is divided into three distinct phases. In the first phase, the attention is focused on the quarry and the objective is to define any change in an observer's visual field, which would be generated by the various possible methods of extraction [27]. The extraction method is the procedure and scheduling of how the mineral deposit is to be subdivided and quarried defining the way in which is progressively removed from the terrain as the extraction work advances. The extraction method is the aspect of the planning phase, which most affects the visual impact of the extraction site throughout its lifetime. Thus, parameters must be chosen to compare different methods, for instance, one parameter may be the quarry lifetime and another the volume of material quarried. These two parameters will be linearly correlated, if it is assumed that the annual production is constant. In the hypothesis presented in this article, a quarry of basalt aggregate is considered with a production rate which is constant over time. Three different methods of extraction for the same site are compared by simulating their various extraction techniques graphically.

Firstly, the layout of the site was defined according to the single-bench quarrying method (i.e. extracting from a single level or bench, then proceeding to the level below once work on the first level has been terminated); the other technique is the method of multiple-bench quarrying (extracting from more than one bench at a time). These two techniques (see Fig. 3) differ from each other in that ecological reclamation may be undertaken in one case (single bench) during the extraction phase and must be left until the end of the lifetime of the quarry in the other case (multiple bench). In contrast to the multiple-bench quarrying methods, single-bench quarrying allows reclamation measures to be carried out following the termination of each bench. Therefore, single-bench quarrying may be subdivided according to whether the reclamation is carried out at the termination of each bench, or if the reclamation is left until the end of the quarry's lifetime.

So far, the evaluation proposed in this article has not yet considered any differences in observers or observation points; only one parameter has been taken into consideration: the exposed area of the quarry [28]. However, the way in which the quarry is perceived by the observer depends on the relative spatial characteristics between the shape of the quarry and the morphology of the surrounding landscape, as well as the amount of the quarried area which may be seen from a given observation point, i.e. the size of the projection of the quarry surface onto a plane which is orthogonal to the direction of the line of vision. To complete the first stage of the analysis, a polar area diagram of 
visibility is constructed, representing the exposed surface area of the excavations which is in the observer's field of view.

In the second stage of the evaluation, the relationship between the morphology of the quarry and the position of the observer is added to the characteristics of the source of the visual intrusion. First, the points from which the quarry is visible were identified in the area surrounding the site. Having defined the visibility map, the area of visibility was then calculated for each time frame throughout the lifetime of the quarry and was correlated with the critical angle of vision. To conclude this second stage, the diagrams of intervisibility [28] were drawn up.

In the final stage, the nature of the observer was incorporated into the process, i.e. once a specific observation point had been identified a suitable impact indicator was determined. This indicator was named the 'Corrected Visual Ratio' and allows other factors to be taken into account such as the characteristic of the observer, either static or dynamic, and other effects such as chromatic contrast between the exposed area of the quarry and the surrounding landscape [29].

This last parameter lends a much greater level of detail to the evaluation, considerably increasing its analytical power, thus providing a tool which would doubtlessly be of use to the planner involved in development of adjoining real estate which is exposed to visual intrusion.

\subsection{The case study}

The case study is in Italy, to the north of Rome in an area called 'Valle Cento' near Nepi, which is in the district of Viterbo. Figure 1 shows the area of interest, which borders with the Regional Natural Park of Bracciano and is located approximately $3 \mathrm{~km}$ from Bracciano Lake and $1.5 \mathrm{~km}$ from the state highway Via Cassia Bis.

Figure 2 shows the orthophotograph of the site $(1: 13,000)$ with the quarry (in red) and the area of specific interest. It is about 16 ha in size and is found to the east of Monte Pogliano hill. The evaluation of the visual impact will be omnidirectional, thus the output will consist of polar diagrams illustrating the impact on various points in the surrounding area. However, a more detailed evaluation will be carried out for the portion of territory shown in blue in Fig. 2, because this land has been chosen as the site for a construction project which is currently still in its planning stages. Since the area also borders to the east with the state highway Via Cassia Bis, an arterial road of national importance, further analysis is required to take into account another type of observer. This blue area covers about 113 ha and Monte Pogliano hill $(305 \mathrm{~m})$ is situated within its boundaries with the Settevene industrial area to the north-east, which backs onto Via Cassia Bis again to the north-east.

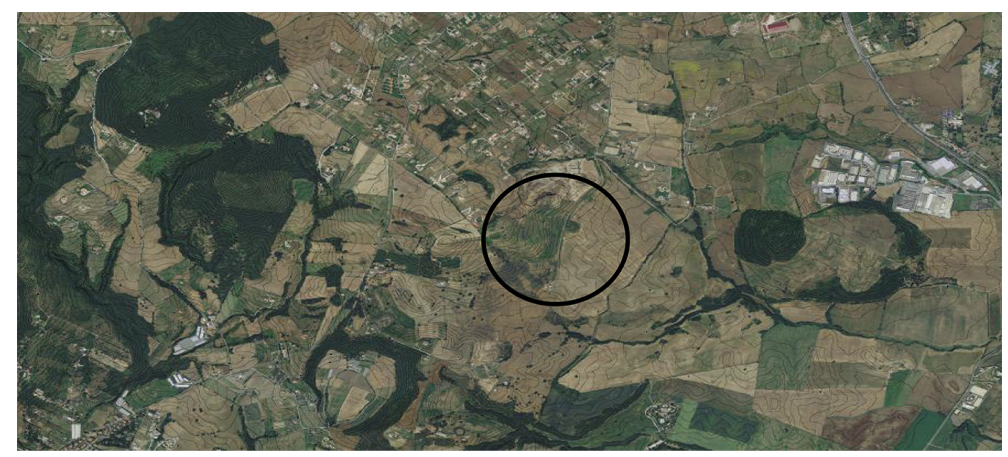

Figure 1: Orthophotograph of the area with the quarry in the black circle $(1: 50,000)$. 


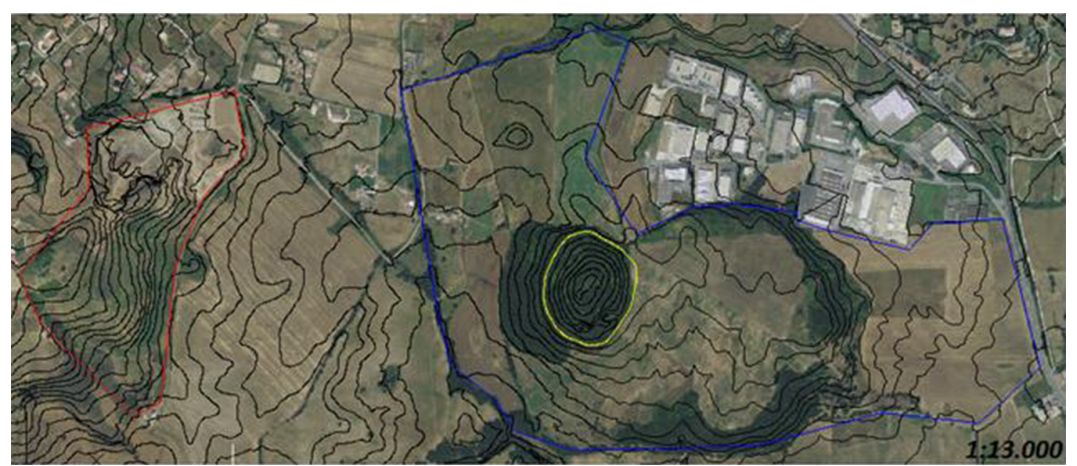

Figure 2: A view of the site $(1: 13,000)$ with the quarry (in red) and the area of specific interest.

\subsection{Simulation of various exploitation methods}

The problem was approached by concentrating on the evolution of the various phases of the quarrying in the extraction site. Starting then from the initial configuration and imposing a constant annual production, the evolution of the various phases of quarrying was simulated for annual time intervals.

The project options evaluated were both for the single-bench quarrying method and the multiplebench quarrying method. The former consists in a subdivision of the deposit into horizontal levels (benches), which are quarried sequentially from the top downwards. Thus, a descending (top-down) method is applied and the material quarried by means of explosives is taken downhill with front loaders and dumpers, which operate on the bench in front of the quarry face. The simulation considers slabs of $10 \mathrm{~m}$ in height, which are removed for a total height of 60 (i.e. 6 successive benches). Although this method has the disadvantage of causing the quarry to evolve horizontally for a considerable distance, it does allow for reclamation to be carried out immediately after a face has been finished. This is the fundamental difference that distinguishes single-bench quarrying in terms of visual impact. In particular in this case study, the restoration technique applied is that of benches backfilling with roll over method. This is the landscape restoration technique whereby the surrounding landform, land use and vegetation are continued into the quarry by tipping and shaping the rim (Fig. 4).

In the case of the multiple-bench method on the other hand, the deposit is again divided into horizontal levels or benches, the height of which may vary between 4 and $15 \mathrm{~m}$. Again in this case, the classic method to quarry the rock is to use explosives. With the project choice of multiple benches, it is clearly important to minimise the movement of blasted material from one bench to the bench below. In this method, the deposit is quarried on several benches (levels) simultaneously.

Figure 3 shows the sequential order that distinguishes the multiple-bench from the single-bench method and illustrates the variation of the latter with and without ecological reclamation being undertaken during the extraction phase.

On applying the parameters given below, the quarry configurations in Figs 5 and 6 are obtained.

\subsection{Visibility analyses}

Once the spatial configurations of the two different project choices are known, the visibility analyses of the quarry are carried out based on three phases as described below. 

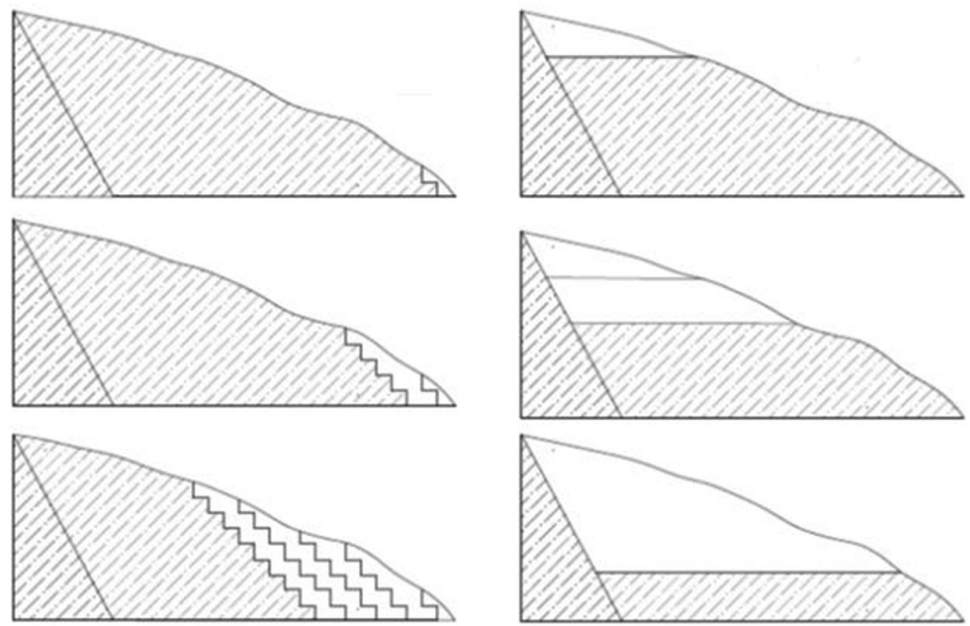

Figure 3: On the left: an example of multiple-bench exploitation method; on the right: the singlebench method.

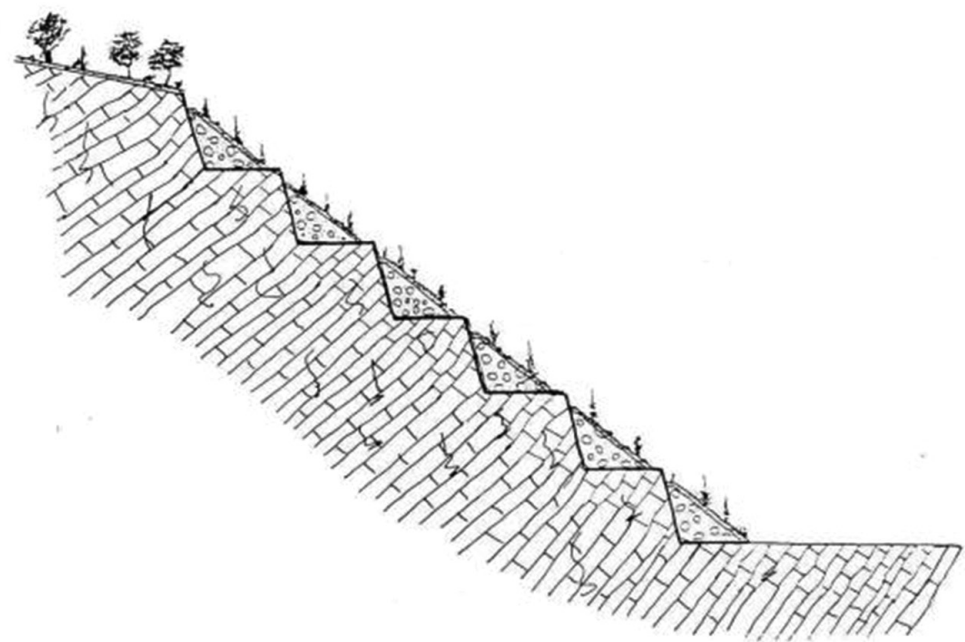

Figure 4: An example of reclamation applied to a quarried surface.

\subsubsection{Polar diagrams}

The parameter of the exposed excavated surface was chosen to quantitatively evaluate the visual impact of the site. This is defined as an extension of the projection of the quarried surface onto an orthogonal plane to the direction of view of a hypothetical observer. When evaluating the area of the exposed excavated surface, both the azimuthal angle and the angle of vision must be borne in mind. In this study, three different angles of vision were chosen $\left(-10^{\circ}, 0^{\circ}, 10^{\circ}\right)$. For each angle of vision, various azimuthal angles were considered, and the projection of the quarry face was analysed and the corresponding surface area was calculated (see Fig. 7). 


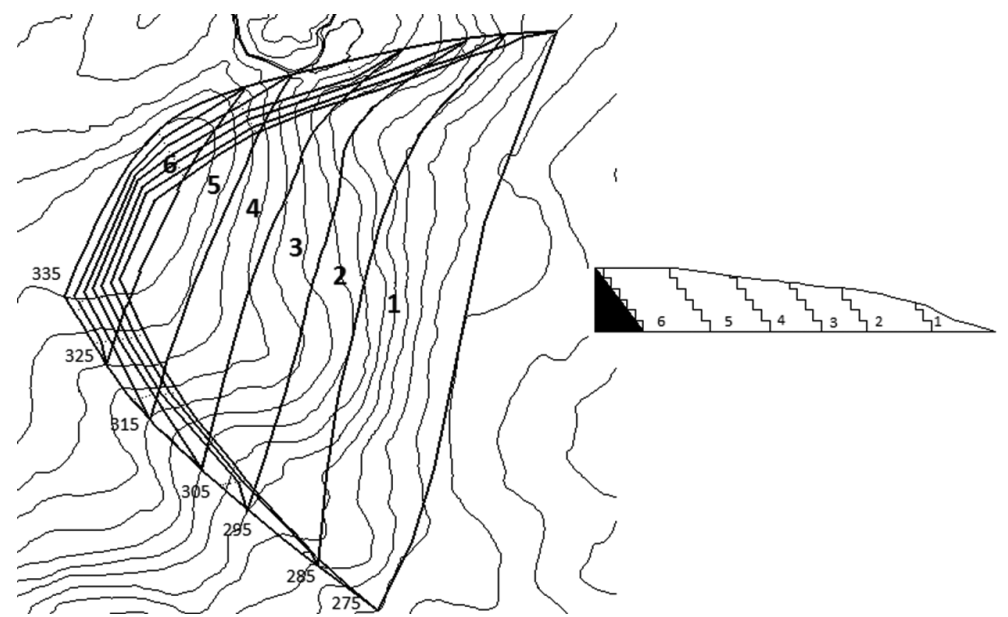

Figure 5: The site with pre-existing contours and quarried contours (multiple bench).

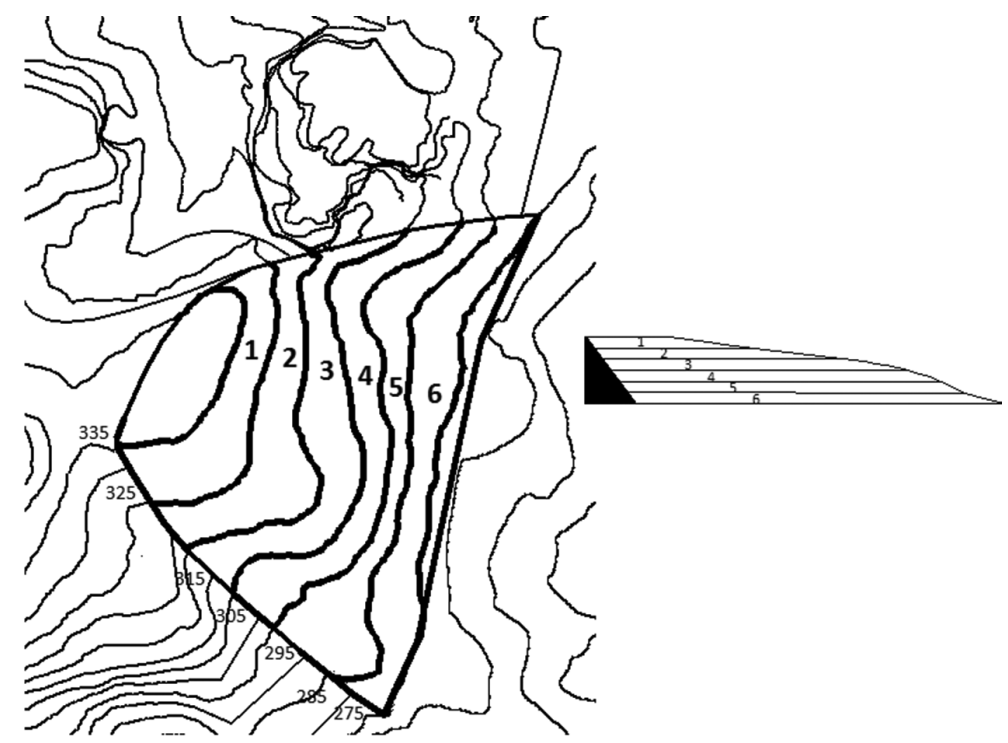

Figure 6: The site with pre-existing contours and quarried contours (single bench).

The use of the polar diagram allowed this information to be visualised directly and effectively. In general, the relevant surface of the excavations has a polyhedral shape which varies over time as the quarrying progresses. However, providing the boundaries of the site and the excavated area in particular do not change, the exposed area may be considered independently from the exploitation method. This feature may be appreciated in Fig. 8 where contours of different methods (single and multiple bench) are within the same limits.

On the basis of this hypothesis, a single polar diagram was realised for both of the project choices. Furthermore, since the dimensions of the quarry site are relatively small, they allow the projection 


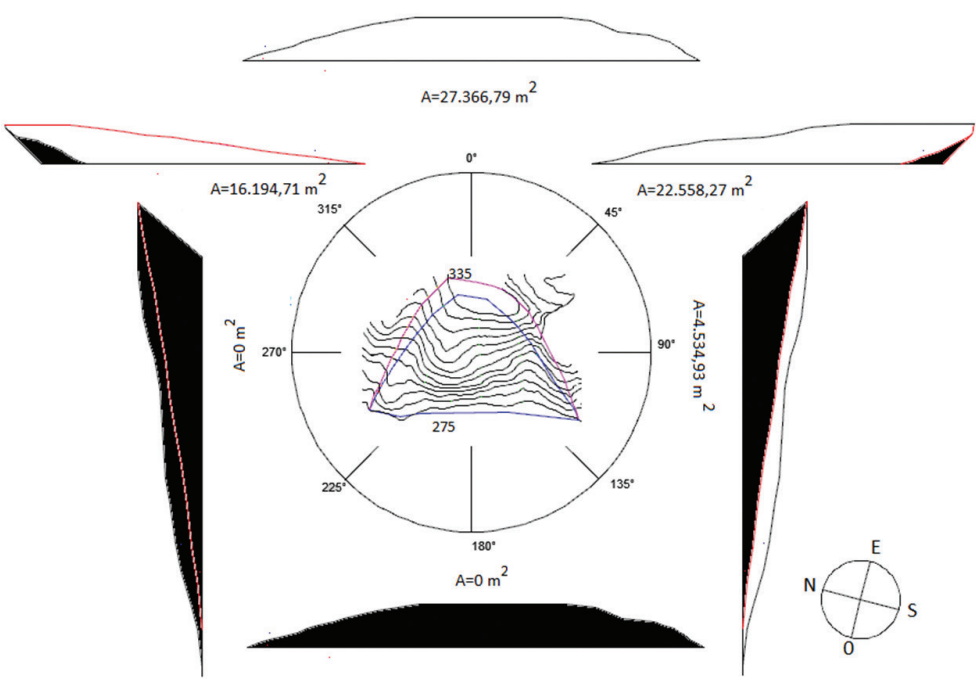

Figure 7: Projection of the quarry from various viewpoints with the relative exposed excavated surfaces.

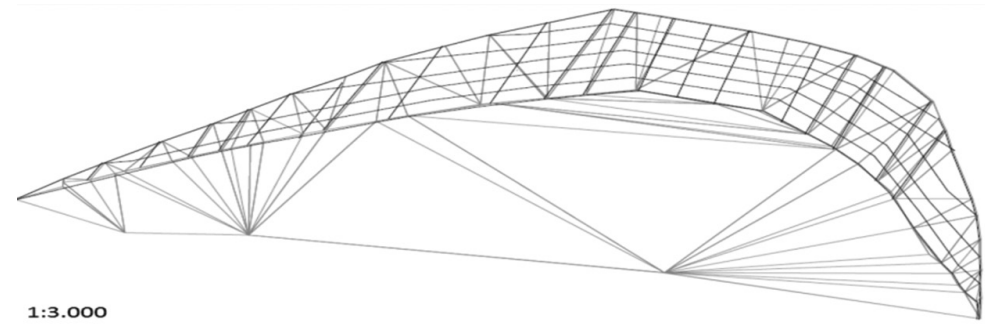

Figure 8: 3D view of the excavated surface (single and multiple benches).

of the quarry to be simplified. The image of the quarry surface is projected onto a plane, which is orthogonal to the direction of the line of vision and its relative size is measured. The calculation was carried out for three different directions of vision. To this aim, it is defined the angle of vision as the angle that the line of vision forms with the horizontal plane and values were assessed for angles of vision equal to $-10^{\circ}, 0^{\circ}$ and $10^{\circ}$ as shown below. A diagram was then constructed for each of the three directions.

It should be noted that this gives a quantitative indication of the relative impact of the characteristics of the site, but any differences due to the various project choices have not as yet been taken into account.

\subsubsection{Diagram of the degree of intervisibility}

From the simulation of the phases of the quarry, it is possible to define visibility maps, i.e. find any points in the surrounding land from which the site is visible, while taking into consideration the changes in the configuration of the quarry over time. Four steps were identified corresponding to 
Table 1: Data of excavated surface at a view direction of $-10^{\circ}$ for some azimuthal angles.

\begin{tabular}{lcc}
\hline Vision angle & Azimuth angle & Excavated surface $\left(\mathrm{m}^{2}\right)$ \\
\hline$-10^{\circ}$ & $180^{\circ}$ & 306.62 \\
$-10^{\circ}$ & $190^{\circ}$ & 404.76 \\
$-10^{\circ}$ & $200^{\circ}$ & 567.38 \\
$-10^{\circ}$ & $215^{\circ}$ & 994.45 \\
$-10^{\circ}$ & $225^{\circ}$ & 1167.43 \\
$-10^{\circ}$ & $230^{\circ}$ & 944.10 \\
$-10^{\circ}$ & $235^{\circ}$ & 100.80 \\
\hline
\end{tabular}

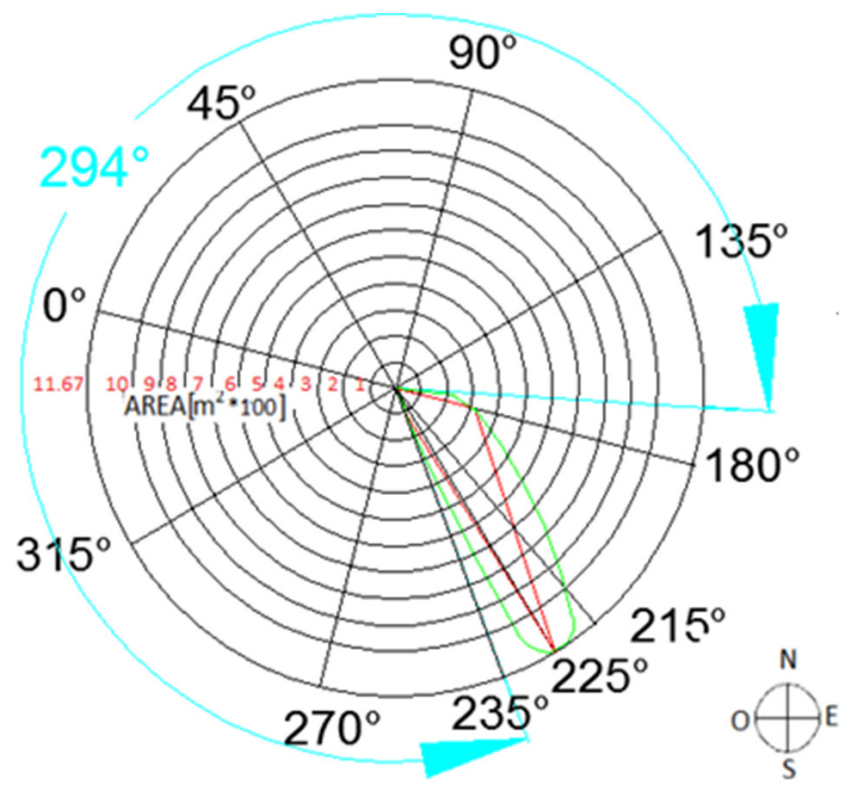

Figure 9: Polar diagram for a view angle of $-10^{\circ}$.

various evolutions of the quarry over time. In particular, in Fig. 12 is shown the visibility map corresponding to the single-bench method when the quarried base surface is at $295 \mathrm{~m}$ on the sea level, and the annual production of quarried material is about $250,000 \mathrm{~m}^{3}$. The area in red corresponds to the visibility area. In Fig. 13, it is shown the visibility map for the multiple bench method corresponding to the same annual production. These are only 2 of 12 maps drawn (four frames for each method). In Fig. 14, the visibility map is drawn for the single-bench method with reclamation (at $295 \mathrm{~m}$ ).

Then, a correlation is performed between the project parameter and the visual impact parameter. In fact, the area of the visibility zone (the extent of the area from which the site is visible) was 
Table 2: Data of excavated surface at a view direction of $0^{\circ}$ for some azimuthal angles.

\begin{tabular}{lcc}
\hline Vision angle & Azimuth angle & Excavated surface $\left(\mathrm{m}^{2}\right)$ \\
\hline $0^{\circ}$ & $100^{\circ}$ & 852.9 \\
$0^{\circ}$ & $112.5^{\circ}$ & 6279.3 \\
$0^{\circ}$ & $123.75^{\circ}$ & 11703.18 \\
$0^{\circ}$ & $135^{\circ}$ & 23541.47 \\
$0^{\circ}$ & $155^{\circ}$ & 27366.69 \\
$0^{\circ}$ & $180^{\circ}$ & 28951.24 \\
$0^{\circ}$ & $202^{\circ}$ & 26892.5 \\
$0^{\circ}$ & $225^{\circ}$ & 22588.27 \\
$0^{\circ}$ & $247^{\circ}$ & 14695.3 \\
$0^{\circ}$ & $258^{\circ}$ & 9754.3 \\
$0^{\circ}$ & $270^{\circ}$ & 4534.93 \\
$0^{\circ}$ & $280^{\circ}$ & 559.60 \\
\hline
\end{tabular}

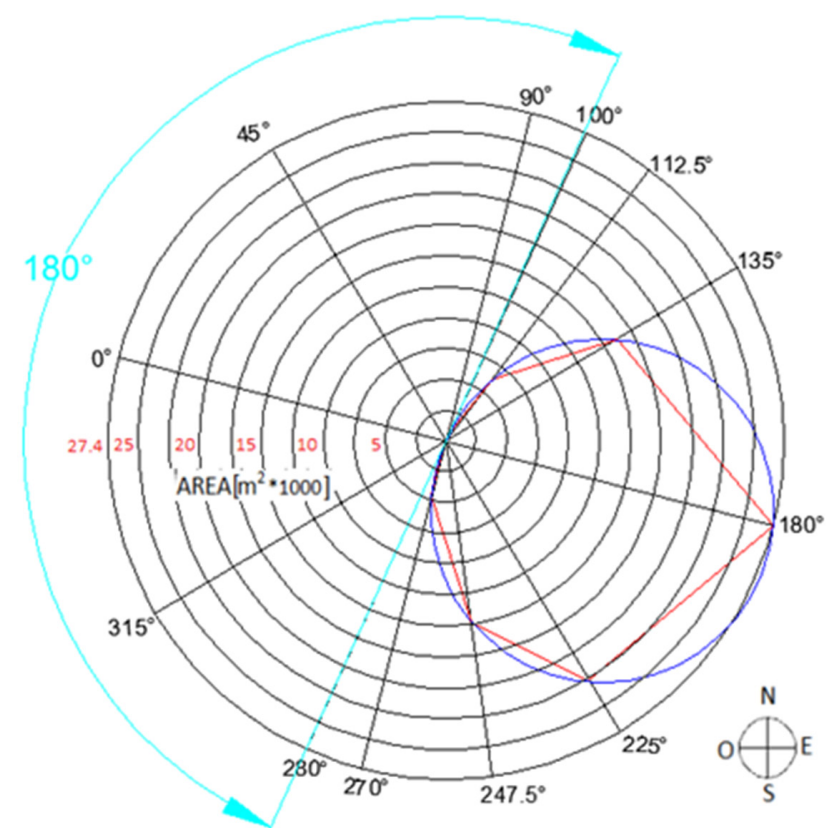

Figure 10: Polar diagram for a view angle of $0^{\circ}$ (horizontal direction).

correlated with the critical angle of vision (see Fig. 15). This last indicates the maximum angle that the line of vision forms with the horizontal plane beyond which the excavated area is no longer visible to the observer. This depends in general terms upon the quarrying method adopted (the 
Table 3: Data of excavated surface at a view direction of $10^{\circ}$.

\begin{tabular}{lcc}
\hline Vision angle & Azimuth angle & Excavated surface $\left(\mathrm{m}^{2}\right)$ \\
\hline $10^{\circ}$ & $44^{\circ}$ & 0 \\
$10^{\circ}$ & $50^{\circ}$ & 3294.76 \\
$10^{\circ}$ & $55^{\circ}$ & 6596.47 \\
$10^{\circ}$ & $70^{\circ}$ & 16248.59 \\
$10^{\circ}$ & $90^{\circ}$ & 27531.54 \\
$10^{\circ}$ & $112^{\circ}$ & 31560.81 \\
$10^{\circ}$ & $135^{\circ}$ & 39403.38 \\
$10^{\circ}$ & $157^{\circ}$ & 46459.73 \\
$10^{\circ}$ & $180^{\circ}$ & 57736.61 \\
$10^{\circ}$ & $202^{\circ}$ & 50301.54 \\
$10^{\circ}$ & $225^{\circ}$ & 44710.20 \\
$10^{\circ}$ & $247^{\circ}$ & 43647.01 \\
$10^{\circ}$ & $270^{\circ}$ & 35813.52 \\
$10^{\circ}$ & $292^{\circ}$ & 26213.93 \\
$10^{\circ}$ & $315^{\circ}$ & 21601.34 \\
$10^{\circ}$ & $337^{\circ}$ & 14515.54 \\
$10^{\circ}$ & $0^{\circ}$ & 4787.55 \\
$10^{\circ}$ & $5^{\circ}$ & 0 \\
\hline
\end{tabular}

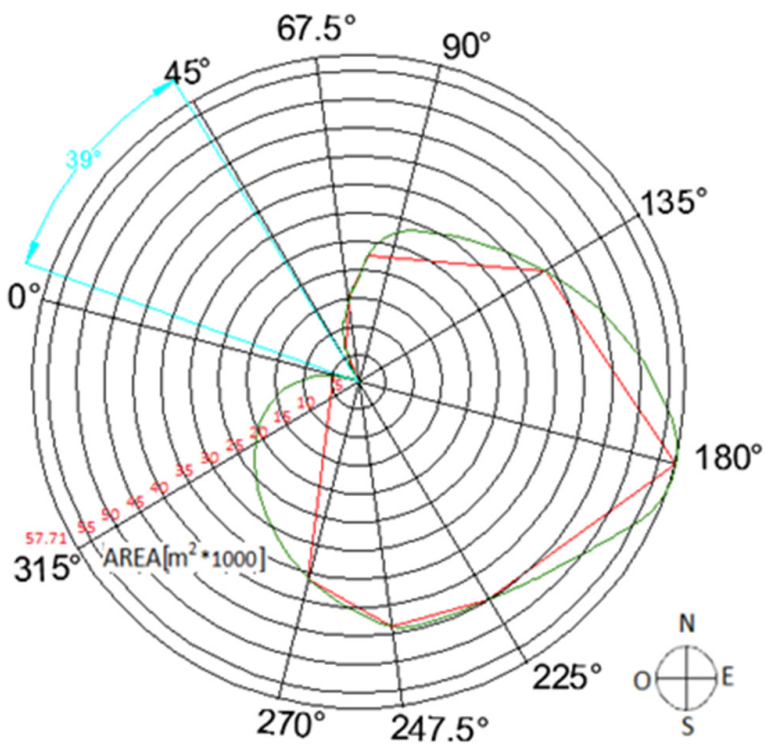

Figure 11: Polar diagram for a view angle of $10^{\circ}$. 


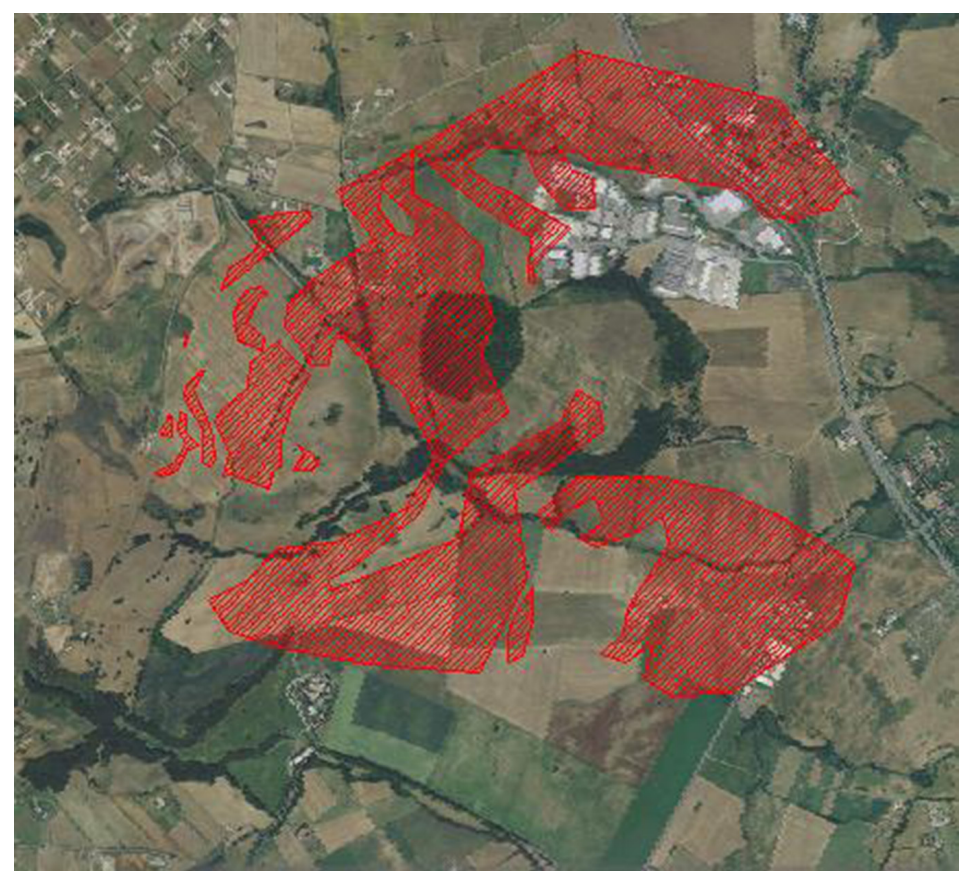

Figure 12: An example of visibility map (single-bench method).

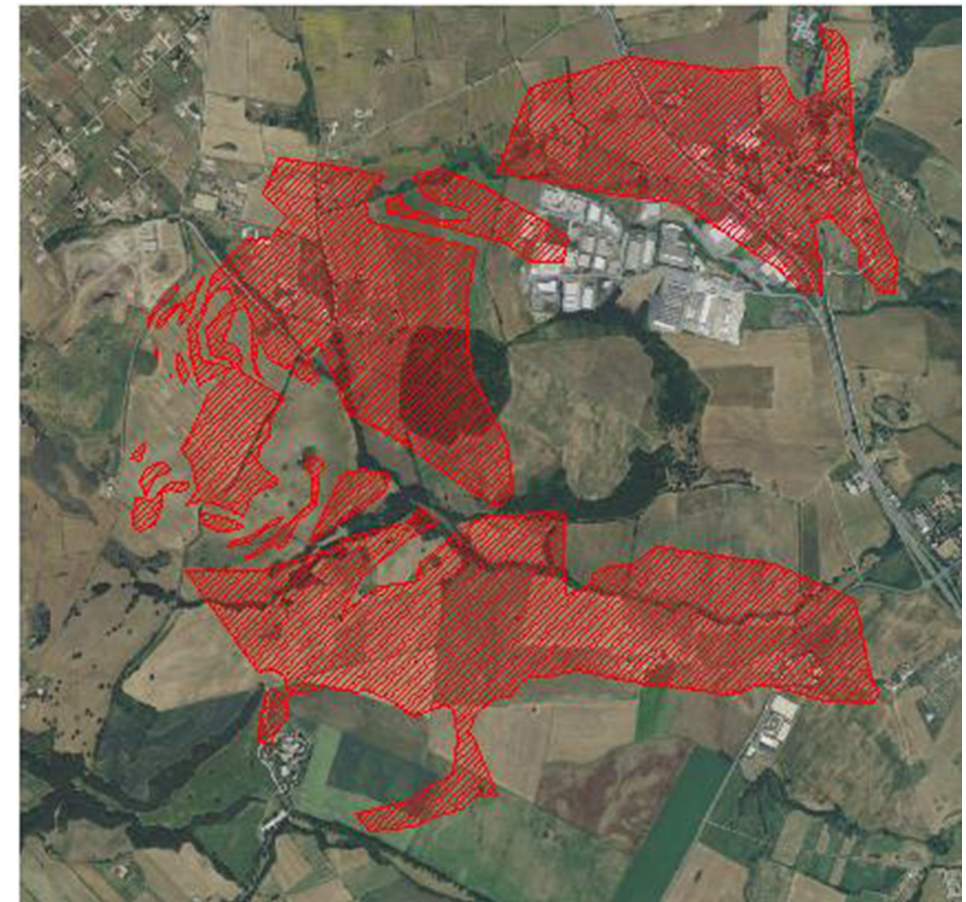

Figure 13: An example of visibility map (multiple-bench method). 


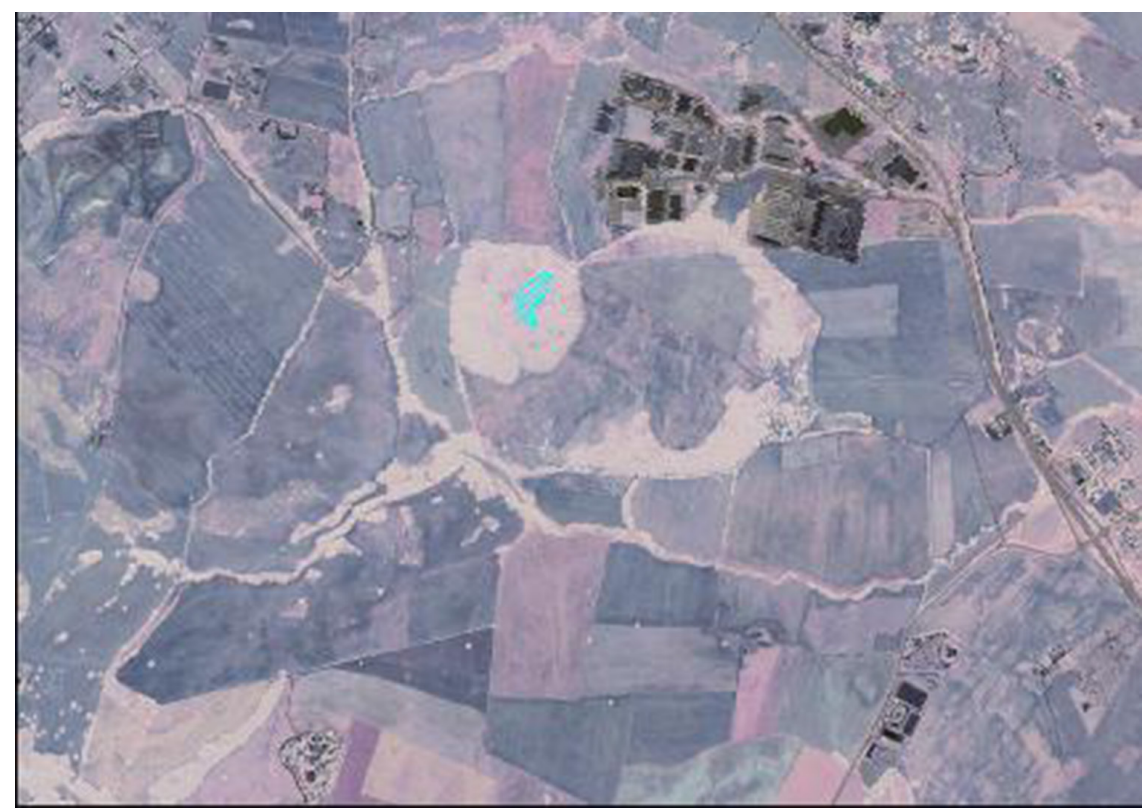

Figure 14: Visibility map (single-bench method with reclamation).

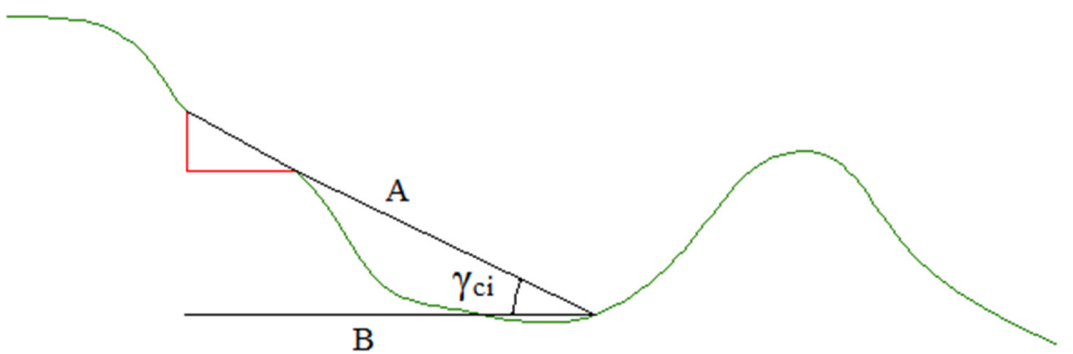

Figure 15: Critical angle of vision.

project choice) and more specifically upon the amount of excavation that has taken place until a given point in time. In the $i$ th direction, the critical angle is defined as

$$
\gamma_{c, i}=\cos ^{-1}\left(\frac{B}{A}\right)
$$

where $A$ is the segment which joins the highest and lowest points of the quarry and the observer; and $B$ is the horizontal distance between the highest point of the quarry and the observer.

The diagram of intervisibility visually indicates the effect that the choice of quarrying method has on the size of the area of visibility. It should be noted that at this stage of our evaluation, neither the 
presence of any observers in the visibility zone nor the magnitude of such visual intrusion has been taken into account.

To construct the diagram, firstly, through the use of the visibility maps (i.e. Figs 12-14), the opening angle of the visibility cone was defined.

Within the azimuthal angle of visibility, a number of visual directions $\mathrm{N}$, appropriate to the size of the quarry, were drawn from the centroid of the quarry outwards through the visibility zone. The critical angle was determined for each direction and the mean value was then calculated as follows:

$$
\gamma_{c, m}=\sqrt[3]{\frac{\sum_{i=1}^{N} \gamma_{c, 1}^{3}}{N}}
$$

where $N$ represents the number of sections considered within the visibility cone, $\gamma_{c i}$ represents the value of the critical angle in the direction identified in the $i$ th section, and $\gamma_{c m}$ represents the value of the mean critical angle within the visibility cone.

The trend of the diagram shown in Fig. 16 allows an order of priority of the methods analysed to be drawn up in relation to the visual intrusion caused to the surrounding area. In the abscissa, the mean critical angle of vision is represented while the ordinate represents the extent of the area of visibility expressed in $\mathrm{km}^{2}$.

\subsubsection{Corrected visual ratio}

Having established the hierarchy of the quarrying methods with regard to visual impact, attention was then directed towards the observers. Even though the size of the visible excavated surface had been quantified, in this last step a parameter was proposed, which can quantify the magnitude of the visual intrusion itself found in the visibility zone. The aim is to define a differentiating criterion, within the visibility zone (i.e. shown in Figs 12-14).

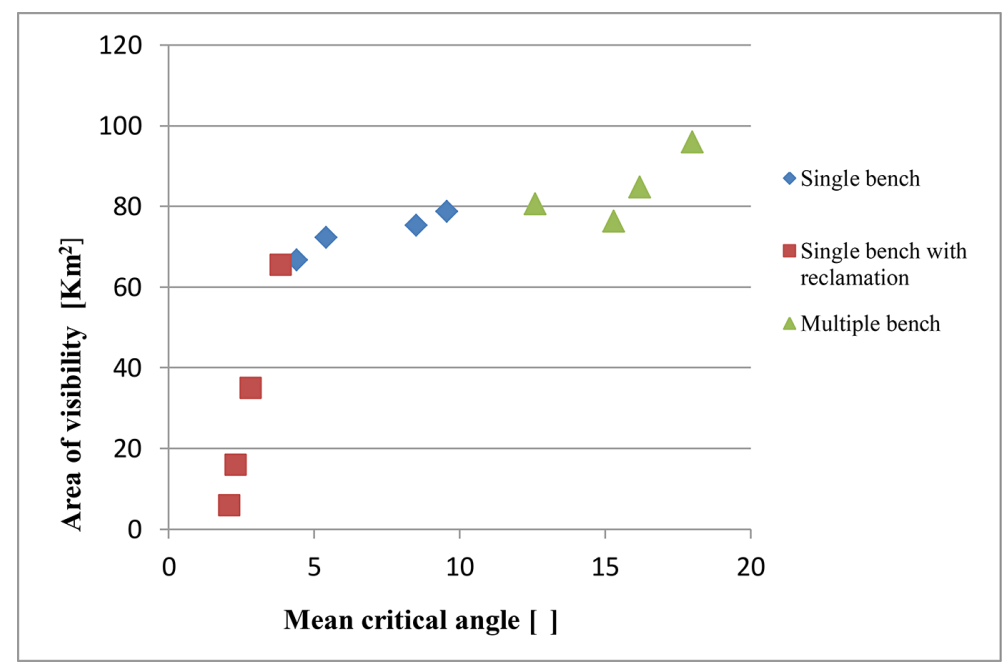

Figure 16: The diagram of intervisibility. 
Taking advantage of the value of the exposed quarry surface in a given direction, it is possible to define the corrected visual ratio from any viewpoint as follows:

$$
V R_{W}=\frac{\Omega_{r}}{\Omega_{x}} \frac{\Delta E_{\mu}}{\Delta E_{B, W}}
$$

where

$\Omega_{r}$ is the solid angle of vision. This is defined as

$$
\Omega_{r}=\frac{A}{d^{2}} .
$$

In which $A$ is the area of the projection of the visible quarry surface onto a sphere, which has the observer at its centre and whose radius is equal to the distance between the quarry and the observer. It is expressed in $\left(\mathrm{m}^{2}\right) . d$ is the distance between the quarry and observer (m). $\Omega_{x}$ is the solid angle, which underlies the area of a spherical sector delimited by a cone of vision whose generators are contained in an angle of $x$ degrees and whose radius is equal to the distance between the source and the observer. $\Delta E_{\mu}$ is the value of the mean chromatic contrast between the quarry area (or a portion of this area) and the surrounding area. $\Delta E_{B, W}$ is the value of the Euclidian distance in CIELAB colour space coordinates, which exists between black and white.

This parameter allows the visual intrusion caused by the quarry to be related to the maximum field of vision that the human eye can discern over the source-observer distance. Moreover, the term $\Omega_{x}$ allows the nature of the observer to be considered; more specifically whether this observer is static or dynamic. The human eye in fact perceives objects within a cone of vision of about $30^{\circ}$ under static conditions. However, should the observer be moving, this angle increases to somewhere between $50^{\circ}$ and $60^{\circ}$, depending on the speed of the observer.

The chromatic ratio allows the difference in colour between the quarried material and the colour of the surroundings to be taken into consideration [30]. This is calculated by means of specially written software, which starts from photographs taken from various viewpoints. The value of $\Delta E_{\text {B.W }}$ is 100 in CIE Lab colour space, as the chromatic coordinates of black and white are, respectively $(L=0 ; a=0 ; b=0)$, and $(L=100 ; a=0 ; b=0)$. In the case examined here, the colour change is from the reddish grey of the basalt to the green of the surrounding vegetation. The value of the chromatic contrast was imposed for each viewpoint as a constant equal to 49.6. The average chromatic ratio used was thus 0.496 . In any event, this may be calculated for each viewpoint, provided that a sufficient number of photographs are available. In the case presented here, the area in question which borders on a state highway (Via Cassia Bis Veientana), the differentiation between the two visibility cones meant defining two distinct Visual Ratios:

$$
\begin{gathered}
V R_{S}=\frac{\Omega_{r}}{\Omega_{30^{\circ}}} \frac{\Delta E_{\mu}}{\Delta E_{B, W}} \\
V R_{D}=\frac{\Omega_{r}}{\Omega_{60^{\circ}}} \frac{\Delta E_{\mu}}{\Delta E_{B, W}}
\end{gathered}
$$

where eqn (5) constitutes the Static Visual Ratio in which the term in the denominator represents the area of the spherical sector delimited by a cone of vision with an opening angle of generators equal 
to $30^{\circ}$, whilst in eqn (6), the same term corresponds to a cone of vision between generators equal to $60^{\circ}$, which is the maximum opening possible for an observer in movement.

The application of this criterion to the area of visibility allowed the construction of a map of visibility, i.e. to quantify the impact of the quarry within the area of visibility.

Given the different types of observers, two distinct maps were realised: one for static observers, i.e. real estate development; and one for dynamic observers, i.e. nearby roads and/or train lines.

It should be underlined that the different maps may not be used to compare one with the other, but illustrate a graphic representation of the impact hierarchies in relation to two different types of observer.

\section{RESULTS}

The evaluation process concludes with the construction of the visibility maps, which present the visual ratio (static or dynamic according to the type of observer) for each point in the area of interest.

In the case studied here, after having refined the procedure, attention is focused on one particular property adjacent to the quarry site in which a civil construction project is underway in its planning stages (see area outlined in blue in Fig. 2).

By way of example, a hypothetical case is considered in which the method adopted is singlebench quarrying with ecological reclamation on completion of each layer. The quarry configuration chosen is that in which the quarried base surface is at $295 \mathrm{~m}$, and the corresponding visibility map is shown in Fig. 14.

The area of the property is superimposed with the area of visibility corresponding to the chosen quarry configuration, obtaining the area in which the visual ratio is defined (static as the observer is not moving).

This is plotted starting from a set of 20 selected points chosen from a squared- shaped grid. For each of these 20 points, a chromatic contrast ratio of 0.496 is hypothesised, while the ratio between the solid angle of vision and the corresponding solid angle of static vision is calculated with the aid of a spreadsheet. The step from the discrete data set to the map was carried out by geostatistical linear interpolation. The interpolation, which permitted the map of VR to be drawn, was performed by means of the geostatistical methodology of simple Kriging with discrete approach [31], using commercial software (Surfer 7.0). In Fig. 17, an example is shown as for the area of visibility on Fig. 14 and the $\mathrm{VR}_{\mathrm{s}}$ parameter is assessed between 15 and 20 (green contours).

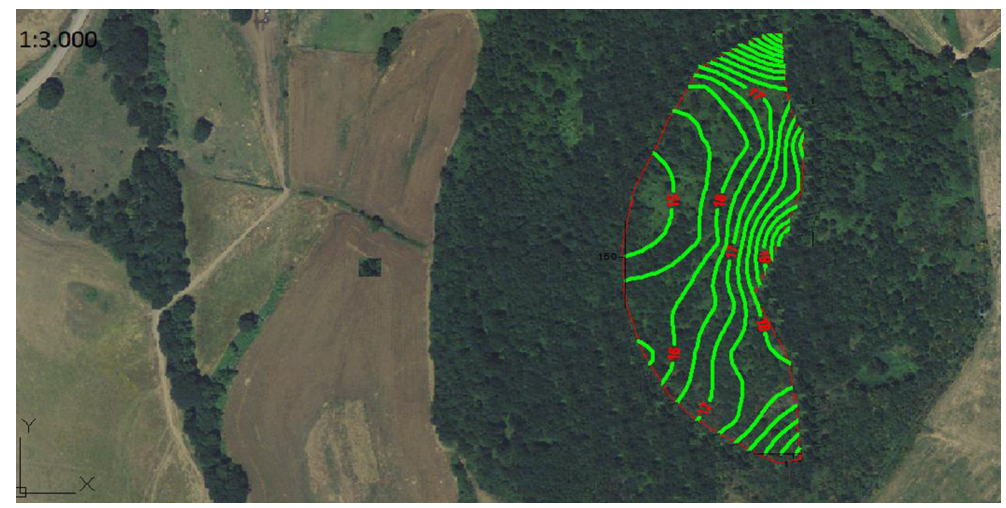

Figure 17: Map of visual ratio all around the selected visibility map. 
Table 4: Correlation between $X$ parameter and qualitative judgement.

\begin{tabular}{lcccc}
\hline & \multicolumn{4}{c}{ Visual impact (intrusion) } \\
\cline { 2 - 5 } & Excellent (minimal) & Good (little) & Sufficient (medium) & Exclusion hardly (severe) \\
\hline Indicator $X$ & $0-10$ & $10-20$ & $20-30$ & $>30$ \\
\hline
\end{tabular}

The final step is that of correlating the quantitative parameter (RV) with a qualitative indicator, which expresses a judgement regarding the degree of visual intrusion caused by the quarry.

This subject is considered according to the provisions stated in the EC decision 272/02 (Commission Decision, 2002) that establishes ecological criteria for the award of the Community eco-label for hard floor-covering.

In particular, this document defines the visual impact indicator $X$ as the ratio between the visible extension of the quarry and the base surface of the visibility cone within which the extraction area can be seen.

The simplification made was that of considering the height and the size of the quarry as being of the same order of magnitude and thus considering only one of the two terms for the calculation of the visual intrusion ( $h^{2}$ in the following formula).

In the formula proposed by the EC Decision 272/02, the vertical dimension is, in fact, considered according to the relationship:

$$
X=\frac{h^{2}}{(L \cdot \operatorname{tg} 30)^{2}} \cdot 100
$$

For the purposes of the present study, the parameter $X$ is proposed since the EU document proposes the quantification of the visual impact and the classification of the results into four categories. Table 4 shows this correlation.

Therefore, without the chromatic contrast, under the assumptions which apply to coefficient $X$, the visibility zone may be subdivided according to the four categories proposed above.

It should be remembered that this correlation only applies to the static RV, since the coefficient $X$ is calculated in relation to the angle associated with the generators of a visual cone equal to $30^{\circ}$.

\section{DISCUSSION}

The analysis of the proposed procedure suggests some considerations. Firstly, taking into account the results of polar diagrams, it should be noted that the extent of the quarried area which is visible to an observer tends to increase as the altitude of the observer increases with respect to that of the quarry. This aspect emerges on comparing the data in Tables 1-3 when the highest value of exposed surface is obtained when the angle of vision is set at $+10^{\circ}$ that is when the observer is looking down over the site from a higher altitude. This results is due to the fact that when viewed from above (a positive angle of vision), the horizontal surface of the quarry is visible to the observer while this is not the case at the same altitude (an angle of vision of zero) or at a lower level (a negative angle of vision) than the source. When the viewing angle is zero or less the horizontal surface of the quarry site remains hidden from view and the only exposed surface is the vertical face (projected onto a plane which is orthogonal to the direction of observation). Similarly, the azimuth angle within which the site is not visible tends to decrease as the altitude of the observer increases. This result is shown 
in Figs 9-11, where the azimuth angle within which the quarry is not visible passes from $294^{\circ}$ to $180^{\circ}$ and finally becoming $39^{\circ}$ when the observer is above the level of the quarried surface (angle of vision $+10^{\circ}$ ).

These outcomes may be considered as one general result varying in accordance with the relative positions of the source (quarry) and the observer. Thus, any further considerations may be generalised if applied to a hill-side quarry, a hill-top quarry or a quarry in the valley floor. Therefore, the main parameter for the assessment of the extent to which a quarried surface is visible must be the relative altitude between the two selected points.

Furthermore, the diagram of intervisibility and its trend suggest some further considerations: the least intrusive exploitation method is that of single bench with reclamation. In the analysed case, the reclamation scheme is that in which quarry waste is backfilled on benches. Finally, in addition to physical re-shaping, a planting technique is then performed to obtain a comprehensive solution.

The other two methods (the single-bench method without restoration and the multiple-bench method) produce a larger area of visibility and a greater critical angle. This implies that these solutions have a greater visual impact on the surroundings and a higher angle of the hill would be needed to screen the intrusive effects generated.

Consequently, the nature of the rock and the site permitting, a quarry adopting the single level or bench method should produce the least intrusive impact on its surroundings.

Lastly, when the area of visibility has been identified, the Corrected Visual Ratio allows a graphical representation of the impact hierarchies in relation to the different types of observer. The final step of establishing a correlation between the quantitative value of the Corrected Visual Ratio and a qualitative judgement needs further explanation. In particular, the quality of the visual intrusion (minimal, little, medium and severe) and its correlation with the Corrected Visual Ratio should still be considered experimental. The hypothesis of comparing value judgements expressed by a sample of potential observers with obtained values is the object of further research.

\section{CONCLUSION}

The evaluation procedure described combines the two main elements of the visual impact; i.e. the source and the observer.

The most important parameters of both components are illustrated to quantify the visual intrusion produced.

The first stage consists in a preliminary project for the extraction process which, in spite of being fairly schematic, manages to outline the most salient aspects of the impact. In this context, the maximum critical angle acceptable, and consequently the most suitable method of extraction, may be defined during the planning stage of the quarry. Thus, by means of an intervisibility diagram it is possible to reduce the plant's area of visibility to a minimum. Clearly, this is not an effective solution to the problem unless there is also a quantitative evaluation inside the area of visibility. The Visibility Ratio represents a possible solution to such a need. Having identified the area of interest which is exposed to the visual intrusion of the quarry, the Visibility Ratio allows the magnitude of the visual intrusion to be quantified by supplying a hierarchy of the effects. Although the effects of the visual impact are qualitative in nature, the Visibility Ratio would undoubtedly be of help to anyone who is required to gauge the effect upon an observer standing inside the area of visibility. The Visibility Ratio constitutes an important aid since it essentially depends on the differences in spatial metrics between the shape of the quarry and the morphology of the site in which it is situated. Analogously, this then, independently from the morphology of the observer's field of vision, may be applied indifferently to areas at various distances from the quarry. This approach may also be utilised to 
compare various observation points around the intended quarry site so as to determine which configuration would produce the least possible impact.

\section{ACKNOWLEDGEMENTS}

Special thanks to Ing. M. De Agostini and Ing. L. Picciolo for their graphical support. This research was developed by the Scientific Research Fund of Roma Tre University, Engineering Dept.

\section{REFERENCES}

[1] Ozcan, O., Musaoglu, N. \& Seker, D., Environmental impact analysis of quarrying activities established on and near a river bed by using remotely sensed data. Fresenius Environmental Bulletin, 21(11), pp. 3147-3153, 2012.

[2] Darwish, T., Khater, C. \& Jomaa, I., Environmental impact of quarries on natural resources in Lebanon. Land Degradation \& Development, 22(3), pp. 345-358, 2011. doi: http://dx.doi. org/10.1002/ldr.1011

[3] Berry, P. \& Pistocchi, A., A multicriterial geographical approach for the environmental impact assessment of open-pit quarries. Proceedings of 6th International Conference on Environmental Issues and Management of Waste in Energy and Mineral Production (SWEMP 2000), ed. R.K. Singhal, A.K. Mehrotra, Balkema, pp. 183-190, 2000.

[4] Dowd, P.A. \& Li, S., Knowledge and geographical information-based system for noise impact assessment of surface mining and quarrying projects. Transactions of the Institution of Mining and Metallurgy Section A-Mining Industry, 109, pp. A1-A13, 2000. doi: http://dx.doi. org/10.1179/mnt.2000.109.1.1

[5] Fisne, A., Kuzu, C. \& Hudaverdi, T., Prediction of environmental impacts of quarry blasting operation using fuzzy logic. Environmental Monitoring and Assessment, 174(1-4), pp. 461-470, 2011. doi: http://dx.doi.org/10.1007/s10661-010-1470-z

[6] Kesimal, A., Ercikdi, B. \& Cihangir, F., Environmental impacts of blast-induced acceleration on slope instability at a limestone quarry. Environmental Geology, 54(2), pp. 381-389, 2008. doi: http://dx.doi.org/10.1007/s00254-007-0825-4

[7] Alfaro Degan, G., Lippiello, D., Lorenzetti, S. \& Pinzari, M., Vibration assessing models: comparison between methods. WIT Transactions on Biomedicine and Health, 16, pp. 59-69, 2013. ISSN: 1743-3525. doi: 10.2495/EHR130061.

[8] Bluvshtein, N., Mahrer, Y. \& Sandler, A., Evaluating the impact of a limestone quarry on suspended and accumulated dust. Atmospheric Environment, 45(9), pp. 1732-1739, 2011. doi: http://dx.doi.org/10.1016/j.atmosenv.2010.12.055

[9] Alfaro Degan, G., Lippiello, D. \& Pinzari, M., Monitoring airborne dust in a Italian basalt quarry: comparison between sampling methods. WIT Transactions on Ecology and the Environment, 174, pp. 75-84, 2013. ISSN 1743-3541, doi: 10.2495/AIR130071.

[10] Vella, A.J. \& Camilleri, R., Fine dust emission from softstone quarrying in Malta. Xjenza, 10, pp. 47-54, 2005.

[11] Alfaro Degan, G., Lippiello, D. \& Pinzari, M., Valutazione sull'efficacia delle metodologie di contenimento dell'emissione di inquinanti aerodispersi in attività estrattive a cielo aperto: un caso di studio nel comparto laziale. Geoingegneria Ambientale Mineraria, 139(2), pp. 5-12, 2013.

[12] Alfaro Degan, G., Di Bona, G., Lippiello, D. \& Pinzari, M., PM10 dispersion model in quarrying activities, a comparison of an ISC3 approach to a mono/multivariate geostatistical estimation. WIT Transactions on Ecology and the Environment, 86, pp. 111-120, 2006. ISSN 1743-3541, doi: 10.2495/AIR06012. 
[13] Alfaro Degan, G., Lippiello, D. \& Pinzari, M., Field evaluation of $\mathrm{PM}_{10}$ detectors in a quarry environment. International Journal of Sustainable Development and Planning, 10(3), pp. 359-370, 2015, doi: 10.2495/SDP-V10-N3-359-370.

[14] Gasparovic, S., Mrda, A. \& Petrovic, L., Landscape models of reclamation and conversion of quarries recovering landscapes. Prestor, 17(2), pp. 372-385, 2009.

[15] Jordan, M.M., Geological and environmental implications in the reclamation of limestone quarries in Sierra de Callosa (Alicante Spain). Environmental Earth Science, 59(3), pp. 687-694, 2007. doi: http://dx.doi.org/10.1007/s12665-009-0065-x

[16] Mouflis, G.D., Ioannis, Z.D., Iliadou, S. \& Mitri, G.H., Assessment of the visual impact of marble quarry expansion (1984-2000) on the landscape of Thasos island, NE Greece. Landscape and Urban Planning, 86(1), pp. 92-102, 2008. doi: http://dx.doi.org/10.1016/j. landurbplan.2007.12.009

[17] Hernandez, J., Garcia, L. \& Ayuga, F., Assessment of the visual impact made on the landscape by new buildings: a methodology for site selection. Lanscape and Urban Planning, 68(1), pp. 15-28, 2004. doi: http://dx.doi.org/10.1016/s0169-2046(03)00116-6

[18] Panagopoulos, T. \& Ramos, B., Aesthetic and visual impact assessment of a quarry expansion. Proceedings of the 2006 IASME/WSEAS Int. Conf. on Energy, Environment, Ecosystems \& Sustainable Development, Greece, pp. 378-381, 2006.

[19] Commission Decision 2002/272/EC of 25 March 2002 establishing the ecological criteria for the award of the Community eco-label to hard floor-coverings. OJ No L, 94, pp. 13-27, 11 April 2002.

[20] Commission Decision 2009/607/EC of 9 March 2009 establishing the ecological criteria for the award of the Community eco-label to hard coverings. OJ No L, 208, pp. 21-38, 12 August 2009.

[21] Bishop, I.D., Assessment of visual qualities, impacts, behaviours, in the landscape, by using measures of visibility. Environment and Planning B, 30, pp. 677-688, 2003. doi: http://dx.doi. org/10.1068/b12956

[22] Massacci, G. \& Dentoni, V. Assessment of visual impact induced by surface mining with reference to a case study located in Sardinia (Italy). Environmental Earth Science, 68, pp. 1485-1493, 2013. doi: http://dx.doi.org/10.1007/s12665-012-1994-3

[23] Menegaki, M.E. \& Kaliampakos, D.C., Landscape analysis as a tool for surface mining design. Environment and Planning B: Planning and Design, 33(2), pp. 185-196, 2006. doi: http:// dx.doi.org/10.1068/b31005

[24] Panagopoulos, T., Matias, R. \& Ramos, B.R., Visual impact and reclamation of limestone quarries in Algarve Portugal. Proceedings of the 24th National Meetings of the American Society of Mining and Reclamation, pp. 176-182, 2007.

[25] Alfaro Degan, G., Lippiello, D., Picciolo, L. \& Pinzari, M., Visual impact from quarrying activities: a case study for planning the residential development of surrounding areas. WIT Transactions on Ecology and the Environment, 181, pp. 125-135, 2014, ISSN 1743-3541, doi: 10.2495/EID140111.

[26] Kumar Dey, P. \& Ramcharan, E., Analytic hierarchy process helps select site for limestone quarry expansion in Barbados. Journal of Environmental Management, 88(4), pp. 1384-1395, 2008. doi: http://dx.doi.org/10.1016/j.jenvman.2007.07.011

[27] Cardu, M., Fornaro, M. \& Sacerdote, I., Economic-environmental description of the exploitation method by horizontal slices and ore pass in Italian surface crushed stone quarries. Proceedings of the 17th International Mining Congress and Exhibition of Turkey (IMCET 2001), pp. 561-566, 2001. 
[28] Pinzari, M. \& Valente, F., Quarry landscape analysis. Quarry and Construction, 8, pp. 17-26, 1992.

[29] Pinto, V., Font, S., Salgot, M., Tapias, J. \& Mañá, T., Image analysis applied to quantitative evaluation of chromatic impact generated by open-pit quarries and mines. Environ Geol, 41, pp. 495-503, 2002. doi: http://dx.doi.org/10.1007/s002540100259

[30] Dentoni, V., Massacci, G. \& Radwanek-Bak, B., Visual impact of quarrying in the Polish Carpathians. Geological Quarterly, 50(3), pp. 383-389.

[31] Alfaro Degan, G., Lippiello, D. \& Pinzari, M., A geostatistical approach to the functional analysis space technique: a case of study. Advances in Safety and Reliability - Proceedings of 16th European Safety and Reliability Conference (ESREL), ed. K. Kolowrocki, Taylor \& Francis, Vol. 1, pp. 45-52, 2005. 